\title{
La construcción de pedagogías descolonizadoras: notas desde la praxis del trabajo en organizaciones sociales*
}

The Construction of Decolonizing Pedagogies: Notes from Work Praxis in Social Organizations

A construção de pedagogias descolonizadoras: notas desde a práxis do trabalho em organizações sociais

\author{
Anahí Guelman** (iD orcid.org/0000-0002-9765-1294 \\ María Mercedes Palumbo ${ }^{* * *}$ (D) orcid.org/0000-0002-9765-1293
}

Artículo de investigación

Revista Colombiana de Educación, N. 7 76. Primer semestre de 2019, Bogotá, Colombia

doi: 10.17227/rce.num76-5929

Para citar este artículo: Guelman, A. y Palumbo, M. (2019). La construcción de pedagogías descolonizadoras: notas desde la praxis del trabajo en organizaciones sociales. Revista Colombiana de Educación, 76, 33-49

\section{(a) (1) $(9$}

* $\quad$ Este artículo surgió en el marco de dos proyectos de investigación UBACYт: "Conocimientos emergentes en propuestas pedagógicas alternativas desde la perspectiva decolonial" (2012-2014), y su continuidad en el proyecto actual: "Prácticas descolonizadoras y formación para el trabajo en los movimientos sociales" (2014-2016). Ambos se inscriben en el Instituto de Investigaciones en Ciencias de la Educación (IICE) de la Facultad de Filosofía y Letras de la Universidad de Buenos Aires y los dirige la Dra. Anahí Guelman.

** Doctora de la Universidad de Buenos Aires, Área Educación. Instituto de Investigaciones en Ciencias de la Educación, Facultad de Filosofía y Letras, Universidad de Buenos Aires, Buenos Aires, Argentina. Correo electrónico: anahiguelman@hotmail.com

*** Doctora de la Universidad de Buenos Aires, Área Educación. Instituto de Investigaciones en Ciencias de la Educación, Facultad de Filosofía y Letras, Universidad de Buenos Aires, Buenos Aires, Argentina. Correo electrónico: mer.palumbo@gmail.com 


\section{Resumen}

El presente artículo parte de las elaboraciones y reflexiones producidas en el contexto del trabajo de investigación de tipo cualitativo realizado en emprendimientos productivos autogestivos-cooperativos desarrollados por una organización social en la Argentina. Se esbozan una serie de notas provisorias en torno a las características que, partiendo de trabajo de campo realizado y en diálogo con los antecedentes investigativos, nos resultan centrales en la conceptualización de las pedagogías descolonizadoras. Como se propone en el artículo, pensar pedagogías descolonizadoras implica abordar el lugar de los saberes y de los sujetos epistémicos otros, la potencialidad del trabajo como principio formativo, la inserción de la formación en la cotidianeidad y la comunidad, la apertura a lo afectivo y, finalmente, el marco colectivo. Las reflexiones desarrolladas en torno a estos cinco aspectos pretenden contribuir a la apertura de horizontes de problematización y discusión sobre las pedagogías en un gesto de descentramiento de la educación colonial.

\section{Palabras clave}

trabajo; praxis; organizaciones sociales; emprendimiento
Keywords

labor; praxis; social organizations; entrepreneurship

\begin{abstract}
The starting point of this article is the statements and reflections made in the qualitative research work carried out in productive entrepreneurships created on self-management and cooperative basis in a social organization in Argentina. A series of tentative notes are presented regarding the characteristics that, as a result of the field work conducted and the dialogue with research precedents, are fundamental in the conceptualization of decolonizing pedagogies. As proposed in the article, thinking about decolonizing pedagogies implies approaching the status of knowledge and other-epistemic subjects, the potentiality of labor as an educational principle, the placement of pedagogy within everyday life and community, the openness to affective realm and, finally, the collective framework. The reflections on these five aspects seek to contribute to the problematization and discussion regarding pedagogy, moving away from colonial education.
\end{abstract}

\section{Resumo}

O presente artigo baseia-se nas afirmações e reflexões produzidas no contexto do trabalho de pesquisa de tipo qualitativo realizado em empreendimentos produtivos autogestivos-cooperativos desenvolvidos por uma organização social na Argentina. Esboçamos uma série de notas provisórias em torno às características que, a partir do trabalho de campo realizado e em diálogo com os antecedentes de pesquisa, consideramos centrais na conceitualização das pedagogias descolonizadoras. Como proposto no artigo, pensar pedagogias descolonizadoras implica abordar o lugar dos conhecimentos e dos sujeitos epistêmicos outros, a potencialidade do trabalho como princípio formativo, a inserção da formação na cotidianidade e a comunidade, a abertura para o afetivo e finalmente, o marco coletivo. As reflexões desenvolvidas em torno a estes cinco aspectos visam contribuir para a problematização e discussão sobre as pedagogias, em um gesto de descentramento da educação colonial.

\section{Palavras-chave}

trabalho; práxis; organizações sociais; empreendimento 
Este artículo se propone socializar y discutir una serie de notas provisorias para abonar a la conceptualización de las pedagogías descolonizadoras surgida en el propio trabajo de vinculación y articulación con movimientos sociales y en diálogo con los referentes académicos del campo de estudios. Estas reflexiones se enmarcan en la apuesta por sistematizar desde la experiencia los componentes de las pedagogías descolonizadoras, ya que, desde la perspectiva descolonial, son escasos los estudios abocados a la temática pedagógica que partan desde las prácticas y experiencias.

En los hallazgos de los proyectos de investigación que sustentan y nutren las consideraciones del presente artículo, trabajamos específicamente con la Interbarrial de Esteban Echeverría, organización integrante del Movimiento Nacional Campesino Indígena ( $\mathrm{MNCl}$ ) de Buenos Aires, indagando y analizando conjuntamente sus procesos de trabajo autogestivo-cooperativo en clave de pedagogías descolonizadoras. La Interbarrial se presenta como una instancia de discusión, intercambio y articulación del trabajo político y productivo desarrollado por el MNCl-Buenos Aires en cuatro barrios populares del Partido de Esteban Echeverría, ubicado en la región suroeste del conurbano bonaerense en la Argentina ${ }^{1}$. Cada uno de estos barrios posee emprendimientos productivos alentados desde la organización colectiva en centros comunitarios: cooperativa textil y criadero de pollos, en el centro Los Sin Techo; cooperativa de dulceras y conservas, en Los Gurises; cooperativa de dulceras, en Remolines, y cooperativa de serigrafía y de producción de pan, en el centro Altos.

Consideramos que la Interbarrial de Esteban Echeverría constituye un caso de análisis particular en cuanto su ubicación geográfica es urbana, pero su participación en el encuadre nacional del mNCı habilita un diálogo con postulados propios de lo campesino y lo indígena, tales como la soberanía alimentaria, la agroecología, la reforma agraria integral; reivindica orígenes campesinos, y apela a saberes ancestrales de sus integrantes. A modo de hipótesis en elaboración, los ámbitos periurbanos en los que se encuentra emplazada la Interbarrial de Esteban Echeverría presentan la condición de "zonas grises", territorios sincréticos que permiten transiciones que unen

1 La historia de esta organización atravesó distintas etapas marcadas por formatos organizativos disímiles y por desplazamientos en los barrios de intervención al ritmo de los cambios en la coyuntura política, social y económica de nuestro país. Esta organización surge en la década de los ochenta con el nombre de Sercupo (Servicio a la Cultura Popular), una organización no gubernamental vinculada a la pastoral cristiana con inserción territorial en los barrios periféricos de la ciudad de Buenos Aires y su área suburbana. Ya en los noventa, con el agravamiento de las condiciones socioeconómicas, realizó un tránsito de lo social a lo político adoptando las banderas y luchas de las organizaciones piqueteras. Finalmente, en la primera década del nuevo milenio, se abrió una nueva fase organizativa a partir del contacto con el Movimiento Campesino de Santiago del Estero (Mocase), su posterior inserción en el Movimiento Nacional Campesino Indígena (MNCI) y el trabajo político específico en el Partido de Esteban Echeverría. 
la urbanidad con la ruralidad. En esta línea, y considerando que de la territorialidad se infieren potencialidades para las prácticas pedagógicas, la articulación entre lo urbano y algunos aspectos de lo campesino e indígena que arraigan en biografías, las prácticas y los saberes de los sujetos que habitan y trabajan en los territorios de la periferia urbana conllevan un aporte potencialmente sustantivo a las prácticas pedagógicas descolonizadoras en el marco de los procesos de trabajo. Adicionalmente, las periferias urbanas permiten el acceso a territorios propios de producción y autoconsumo que podrían habilitar mayores márgenes de autonomía respecto a la lógica mercantil, en el encuentro con esas biografías, prácticas y saberes.

En nuestro abordaje, retomamos las consideraciones teóricas que plantean el principio formativo del trabajo (Gramsci, 2009), lo que nos permite anudar trabajo y pedagogía. Consideramos que los procesos de trabajo autogestivo-cooperativo en movimientos sociales constituyen uno de los ámbitos donde se inscriben y se gestan cotidianamente las pedagogías descolonizadoras latinoamericanas. En estos ámbitos específicos, observamos ciertas lógicas que cuestionan las formas productivas, epistémicas y pedagógicas tradicionales y que aportan a la sistematización de una serie de componentes más generales propios de las pedagogías descolonizadoras.

Al mismo tiempo, ubicamos una serie de claroscuros en los procesos de formación en el trabajo que conducen a preguntarnos por la complejidad y las contradicciones del desarrollo concreto de esas pedagogías. Entre los claroscuros, destacamos cuestiones referidas a la feminización del trabajo autogestivo, la división entre trabajo manual e intelectual, los bemoles de las vinculaciones entre lo individual y lo colectivo y, finalmente, las posibilidades de la proyección en lo político desde los emprendimientos productivos. Las contradicciones señalan que en el seno de estos emprendimientos productivos se muestran, de manera simultánea, las resistencias de un modo hegemónico de vida, un patrón de poder y un modelo de conocimiento, así como la potencialidad de desafiarlo.

Este artículo presenta cinco secciones que abordan una serie de notas provisorias en torno a las características que, partiendo del trabajo de campo realizado y en diálogo con los antecedentes investigativos, nos resultan centrales en la definición de las pedagogías descolonizadoras. A continuación, se presentan los principales argumentos esbozados y se sugieren líneas de indagación complementarias a desarrollar en futuros trabajos. 


\section{Notas provisorias sobre las pedagogías descolonizadoras}

Ante el convencimiento de su necesidad política y ética, nos planteamos la indagación de la posibilidad y la potencia de las pedagogías descolonizadoras. Nos interesa analizar las prácticas que pueden desenvolver ese aporte potencial a la construcción de pedagogías que contribuyan a resquebrajar la lógica del patrón de poder moderno/colonial (Quijano, 2003). Por ello, buscamos pistas y claves en ámbitos corridos de las lógicas tradicionales, tanto educativas como productivas y políticas.

Asumimos algunos de los rasgos planteados por autores preocupados por la descolonización pedagógica como la comprensión crítica de la historia (no neutral ni aséptica), la recuperación y reposicionamiento de los legados de prácticas y saberes pedagógicos emancipatorios y el cuestionamiento a los enfoques epistémicos hegemónicos descontextualizados, eurocentristas, en fin, coloniales (Díaz, 2010; Walsh, 2009). Consideramos también otros componentes, como el cuestionamiento a la falsa pretensión de inclusión multicultural de los excluidos (Walsh, 2009), la revisitación de una serie de pedagogos latinoamericanos, entre los cuales se destacan Frantz Fanon y Paulo Freire (Fernández Mouján, 2013; Walsh, 2009, 2013) y la configuración de horizontes utópicos en lucha contra el eurocentrismo (Cabaluz Ducasse, 2015). No obstante, nos parece central poner en diálogo estos postulados teóricos con la empiria - con prácticas y experiencias concretas - con vistas a reflexionar acerca de en qué consistirían las pedagogías descolonizadoras.

La opción por nombrar a las pedagogías como descolonizadoras, en vez de la adjetivación más usual en términos de pedagogías decoloniales (Cabaluz Ducasse, 2015; Walsh, 2009, 2013), descoloniales (Fernández Mouján, 2013) o en clave decolonial (Díaz, 2010), radica en tres aspectos. Por un lado, se presenta como una categoría más amplia en sus referencias conceptuales que incluye al grupo Modernidad-Colonialidad, pero abarca un abanico más amplio de pensadores que se inscriben en el pensamiento crítico del tercer mundo así como de pedagogías colectivas llevadas adelante por actores sociales en sus prácticas cotidianas de organización. Asimismo, a nivel semántico, lo descolonizador reenvía a un verbo, a una acción, a una propuesta en acto y despliegue que nos resulta central en su capacidad de articulación de teoría y práctica. Finalmente, consideramos que la coyuntura actual latinoamericana impone la inquietud por repensar la colonización -y no solo la colonialidad — como un proceso que aún no se encuentra cerrado.

Coincidimos con Restrepo y Rojas (2010) cuando alertan respecto a la distinción analítica entre descolonización y decolonialidad, derivada de la diferencia entre colonialismo y colonialidad: mientras la primera remite 
a la superación del colonialismo, la segunda supone subvertir el patrón de poder moderno-colonial en todos los dominios de la experiencia humana, así como la apertura a nuevas prácticas y discursos alternativos que reconozcan la herida colonial y reivindiquen a quienes fueron fragilizados por el patrón de poder colonial. No obstante, insistimos en que el uso de la idea de descolonización en este artículo problematiza el cierre del proceso de superación del colonialismo con las luchas anticoloniales.

En nuestras primeras aproximaciones a la temática, intentamos también establecer ciertos supuestos que podían contener estas pedagogías, como la presencia de utopías, la relación dialéctica entre teoría y práctica, la marca de algunos de los pedagogos latinoamericanos, la fuerte vinculación con la política y una praxis participativa e incluyente. Pero fuimos necesitando encontrar, más acá de las formulaciones teóricas y de nuestros propios supuestos, los modos operativos y concretos de una pedagogía que posibilitara construir procesos descolonizadores, observar pistas acaeciendo, funcionando en praxis reales, que nos permitieran plantear cómo se lleva adelante y se pone en acto una pedagogía que ayude a romper un patrón de poder y a constituir sujetos que lo cuestionen.

En el trabajo de campo que desarrollamos, junto y en la Interbarrial de Esteban Echeverría, fuimos observando, participando e interpretando procesos que nos permitieron incipientemente pensar en algunos de los siguientes tópicos como rasgos de las pedagogías descolonizadoras: a) el lugar de los saberes y de los sujetos epistémicos otros, b) el trabajo como principio formativo, c) la inserción en la cotidianeidad y la comunidad, d) la apertura a lo afectivo y, finalmente, e) el marco colectivo.

\section{El lugar de los saberes y de los sujetos epistémicos otros}

Partimos de la premisa de que en los emprendimientos productivos autogestivos-cooperativos analizados se cuestionan — con intensidad variable- las matrices epistémicas que exaltan el conocimiento académico y confinan al lugar de subalternidad, carencia e ignorancia a la pluralidad de saberes populares existentes en América Latina. Adicionalmente, al revisar los saberes y conocimientos valorados en estos emprendimientos también los sujetos participantes atraviesan una reconfiguración de su posición epistémica respecto a considerarse meros receptores de conocimientos producidos por otros para pasar a percibirse como portadores de saberes valiosos.

La epistemología crítica de Sousa Santos aporta categorías y perspectivas de análisis a este respecto. Según el autor, lo "no existente es producido activamente como no existente" (Santos, 2006, p. 23). La forma 
de producción epistémica de estas ausencias radica en la monocultura del saber y del rigor que equipara el conocimiento con el producto de la ciencia occidental, con el conocimiento fundado en las disciplinas del saber. En consecuencia, la diversidad epistémica se encuentra amenazada por la catalogación como saberes ausentes o no-existentes de una serie de epistemes que no se atienen a los cánones de la ciencia, angostando el campo de la realidad relevante y delimitando una "línea abismal" que separa lo verdadero, lo universal, lo objetivo, lo neutral (la ciencia) de lo falso, lo particular, lo no científico (otros saberes). Para Santos, Meneses y Arriscado Nunes (2004), la virtualidad del epistemicidio ocurre en la negación de la pluralidad de epistemes que conviven cotidianamente con la ciencia en una relación de subordinación fundada en el privilegio epistémico y sociológico adjudicado al conocimiento científico.

En la génesis de la perspectiva epistémica colonial, siguiendo el análisis del giro decolonial, se encuentra la separación sujeto-objeto cartesiana fundante de la modernidad sobre la cual se asentó una concepción de conocimiento basado en la separación radical entre el hombre que conoce y el objeto (el mundo o incluso otros sujetos) que es conocido (Lander, 1993). El sistema escolar, heredero de esta matriz moderna tal como se desarrollará en las próximas notas, reafirma la legitimidad del estatuto de los conocimientos académicos. Estos son validados como único registro epistémico en la escuela, dada su inscripción en las matrices simbólicas de la modernidad (Díaz, 2010), por lo que se descuidan los saberes vitales y existenciales de los alumnos.

En este sentido, en los emprendimientos productivos observados, los "saberes del Sur" son rescatados y puestos en valor: cría de animales, saberes de plantas medicinales, hábitos de consumo, recetas culinarias, saberes sobre costura, formas de relacionamiento con la tierra, acceso a la experiencia de lo comunitario. La noción de saberes del Sur (Santos, 2010) remite a este conjunto diverso y disperso de saberes populares que no responden al canon del conocimiento social y escolarmente valorado como digno de ser enseñado, aprendido y transmitido ${ }^{2}$. Estos saberes

2 Concebimos los "saberes del sur" de un modo complejo, negando asociaciones lineales con un carácter exclusivamente emancipador. En esta línea, resulta relevante el abordaje de Bonfil Batalla (1997) respecto a la cultura popular, asidero de los saberes del sur. En función de la relación entre el grupo social con capacidad de decisión (que ejerce un control cultural) sobre los elementos culturales y el tipo de elementos culturales sobre los cuales se decide según sean — en ambos casos - propios o ajenos, establece una tipología entre cultura autónoma, apropiada, enajenada o impuesta. En este sentido, la cultura es un campo abigarrado, contradictorio e híbrido donde coexisten elementos emancipadores y reproductores. 
devienen, a menudo, saberes técnicos, políticos y subjetivos ${ }^{3}$ dispuestos para la creación y potenciación de los proyectos autogestivos-cooperativos de la Interbarrial.

Si partimos de la consideración respecto a que muchos de los integrantes de los grupos productivos —o sus padres - provienen de países limítrofes o de distintas provincias del interior del país, en estos intercambios se rescata una memoria de saberes, saberes del campo, saberes de origen, saberes ancestrales que se resignifican cuando se despliegan en el nuevo contexto periurbano propio del conurbano bonaerense. Nos resulta de particular riqueza este encuentro que recupera saberes y muestra la potencia del encuentro entre lo viejo y lo nuevo, entre lo portado y lo que fueron construyendo. En este sentido, la categoría de ecología de saberes apunta a visibilizar una configuración epistémica plural que habilita una comunidad de discursos y prácticas más amplia y menos excluyente que la monocultura del saber y del rigor científico (Santos, 2006).

Adicionalmente al rescate de una configuración epistémica plural que revierte la equiparación entre conocimiento y ciencia, notamos que en los emprendimientos productivos se modifican las relaciones en torno al conocimiento. Más que relaciones entre maestros y alumnos que evocan a la desigualdad escolar en torno a la posesión o carencia de conocimiento, aquí se presentan vínculos entre sujetos portadores de saberes distintos, aunque igualmente valiosos. De lo anterior se desprende que todos pueden constituirse como educadores, aunque no todos posean el mismo saber para ser compartido y enseñado.

En esta línea, se repiten en los integrantes de los grupos productivos expresiones referidas al aprender haciendo entre compañeros y reflexiones relativas a reconfiguraciones epistémicas en el acto de enseñar lo que se sabe (basado en el reconocimiento de la posesión de un saber) y en el acto de dejarse enseñar por un compañero del emprendimiento productivo, rompiendo la fragmentación y atomización del saber asociada a la división especializada del trabajo.

3 En Guelman y Palumbo (2015), se trabajó una clasificación de los saberes presentes en los emprendimientos productivos de la Interbarrial de Esteban Echeverría en términos de saberes técnicos asociados directamente a la experiencia de la producción (al "saber hacer" que esta implica), saberes políticos vinculados a la condición organizativa y colectiva que dio origen y tracciona los grupos productivos; y finalmente saberes subjetivos referidos a la dimensión vincular anudada a la producción tanto dentro como fuera de los emprendimientos productivos. 


\section{El trabajo como principio formativo}

Sostenemos desde la pedagogía y su historia que el trabajo es una praxis que forma y educa sujetos. Era precisamente en el trabajo donde se formaban los campesinos y los artesanos antes de la consolidación de los sistemas educativos modernos. Pero es también en el trabajo donde hoy siguen formándose los sujetos, en términos técnicos y en términos sociales. Creemos, en este sentido, junto con Gramsci (2009), en el principio formativo del trabajo, porque en el proceso de trabajo el trabajador articula su acción, su pensar, aprende modos y técnicas para operar y sus fundamentos, y articula este saber sobre el trabajo y sobre las relaciones en las que se produce. Los saberes acerca de la naturaleza que el hombre transforma en el trabajo, los saberes acerca de la sociedad y de sus leyes y los saberes de los derechos se articulan en el marco del trabajo. Por eso uno de los principales aprendizajes del trabajo como principio formativo es el de las relaciones sociales, el disciplinamiento, socialización y naturalización o bien la desnaturalización de las condiciones de vida y del funcionamiento de lo social.

Parece fundamental, entonces, comenzar caracterizando los proyectos productivos que observamos en la Interbarrial de Esteban Echeverría para comprender su papel en la formación de sus trabajadores. Son parte de una economía de subsistencia que funciona de manera colectiva y sin patrón. Se trata, por lo tanto, de procesos de trabajo que parecen no corresponderse con lógicas acumulativas, en los que no hay relaciones salariales ni plusvalía. Si bien estas formas podrían remitir a situaciones premodernas, precapitalistas o precoloniales, decimos, con Quijano (2010), que las formas que asume el trabajo en el seno del patrón de poder moderno/colonial y capitalista — aun las no salariales — se encuentran todas articuladas al capital. En este sentido, si el trabajo autogestivo-cooperativo aporta alguna lógica descolonizadora, no es la de ser "pre-" capitalista, moderna o colonial, sino la de la posibilidad de atravesar la modernidad colonial capitalista cuidando y transmitiendo algunos valores y parámetros no coloniales como el valor de lo colectivo, el establecimiento de vínculos y relaciones entre sujetos que no se diferencian por el hecho de poseer o no los medios de producción (o la propia fuerza de trabajo), que no venden su fuerza de trabajo, sino que la usan asociados a otros y que no buscan acumular riqueza.

Desde este punto de vista, incluso en la complejidad que plantea la articulación al capital, el trabajo en proyectos productivos autogestivos-cooperativos parece desempeñar un papel en la transmisión de valores o formas de vida propios, con vínculos no mercantilizados, y también formar sujetos en este mismo sentido. De allí que las particularidades de los modos de trabajar y producir en las experiencias productivas de

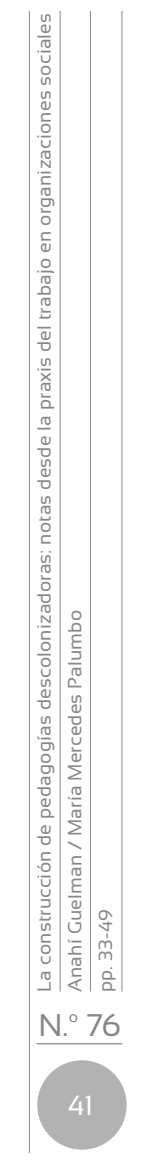


este movimiento social quizá puedan trastocar ciertas lógicas modernas/ coloniales y capitalistas de producción, en cuanto que en sus proyectos productivos prima lo colectivo y lo no acumulativo.

Por otro lado, en los emprendimientos analizados se establecen relaciones diferentes con la naturaleza, que buscan respetarla en línea con los postulados de agroecología, soberanía alimentaria y reforma agraria integral del encuadre nacional del Movimiento Nacional Campesino Indígena (MNCI), presente igualmente en la Interbarrial de Esteban Echeverría. Estas consideraciones se imbrican con las tematizaciones respecto a la colonialidad de la naturaleza (Escobar, 2003), en el marco de la perspectiva del denominado giro decolonial, que asocian su mercantilización y su consecuente colonización a las maneras de asumir, consumir, enfrentar y actuar con, sobre y desde la naturaleza en la modernidad-colonialidad.

Pero, fundamentalmente, los grupos productivos en estudio plantean una vinculación diferente entre sujetos iguales que pueden ser protagonistas de su proceso de trabajo, que pueden discutir, planificar, enseñar el trabajo, que lo materializan y ejecutan y pueden también establecer políticas y estrategias de comercialización. Aun cuando este sea uno de los puntos más difíciles de llevar a cabo, parecería que los sujetos trabajadores de los proyectos productivos pueden llevar adelante el proceso de trabajo de principio a fin, contribuyendo a encontrar y fijar su sentido. Es decir, el trabajo produce y permite también analizar lo producido. Es lo concreto y la materialidad, pero también va más allá en la medida en que habilita el análisis de esa materialidad.

El trabajo como espacio de formación es parte de la cotidianeidad, de la vida misma y de sus condiciones. No artificializa el aprender, sino que lo hace conectando con la vida material y social. En este sentido, se erige en pedagogía de la praxis, donde los procesos de reconfiguraciones subjetivas parten de las prácticas productivas y de la prefiguración de nuevas relaciones sociales en el mismo hacer en el que se transforma la naturaleza dando sentido humano a lo natural. La praxis, para Kosik (1986), implica, además de la conjunción entre lo manual o físico y lo intelectual, entre la ejecución y la concepción, lo que él llama lo existencial o que puede ser denominado como lo emocional, lo gnoseológico, lo subjetivo. Es en este hacer que implica todos estos aspectos, que el trabajo articula la formación de sujetos en praxis concretas, que la formación es "en" el trabajo.

\section{La cotidianeidad y la comunidad}

Este es precisamente el punto que nos trae el tercer aspecto que nos interesa respecto de las pedagogías descolonizadoras en cuanto a los ámbitos de la formación y de la construcción de aprendizajes. La modernidad/ 
colonialidad trae también la novedad de la delimitación de los ámbitos de formación, de su constitución en espacios específicos, separados del resto de la cotidianeidad de los sujetos. Los Estados nacionales requieren de espacios ad hoc, espacios cerrados que destruyen las lógicas de socialización y formación de las etapas anteriores (Varela y Álvarez Uría, 1991) para la formación de sus ciudadanos y trabajadores.

Este proceso de constitución de instituciones educativas específicas y cerradas, consolidadas finalmente como sistemas educativos, no fue privativo de Latinoamérica. En Europa se buscaba disputar con el régimen feudal. Pero, en nuestro caso, tuvo características propias vinculadas al orden colonial y neocolonial: las colonias primero, y los Estados-nación después, tenían que negar, ocultar y matar las culturas originarias, el mundo cultural amerindiano (Dussel, 2012), conquistando, oprimiendo y dominando a través de un proceso de adoctrinamiento en esas instituciones específicas. Para Dussel, en la Argentina de fines del siglo xIx, la Ley 1420 de educación gratuita y obligatoria cristaliza la negación de la cultura popular y la intención de introyección en el pueblo de la cultura de la burguesía ilustrada dependiente. En sus palabras:

Así nace la institución pedagógica moderna, la Escuela del Estado burgués primero, imperial después, neocolonial simultáneamente, que niega lo anterior (la cultura feudal) y oprime lo popular (la cultura popular en la periferia: nuestra cultura dis-tinta y en parte autóctona). (Dussel, 2012, p. 585).

El sistema educativo argentino así creado se torna exclusivo, distorsiona, aliena y condiciona de acuerdo con las necesidades de las sociedades colonizadas y burguesas. Por eso, Dussel reclama superar la concepción "exclusivamente escolar del proceso educativo [...] tan inadecuada" (Dussel, 2012, p. 610) para construir una educación comunitaria y dialógica.

Algo del orden opuesto a la lógica anterior de los espacios cerrados es lo que encontramos en proyectos de producción del movimiento social con el que trabajamos. Se trata de espacios no exclusivos, no separados de la cotidianeidad y lo comunitario, en los que se aprende y se construye saber: los saberes que se transmiten no son construidos en otros ámbitos separados del contexto de su reproducción. La producción y la reproducción de los saberes en el trabajo autogestivo-cooperativo van de la mano, así como lo hacen la producción y la reproducción de la vida de los sujetos integrantes de los emprendimientos. En esa circulación de saberes, se rompe con la lógica binaria del poder del saber en la cual quien lo posee lo transmite a los que no saben. Más bien se trata, al menos en potencia, de que todos enseñen y aprendan juntos rompiendo la lógica de la transmisión vertical propia de los sistemas educativos escolares (Guelman, Dyzel y Corvalán, 2016). 
Si en la nota referida al lugar de los saberes y sujetos enfatizamos la potencialidad del nexo entre el rescate de los saberes del Sur — saberes complejos y de ningún modo linealmente emancipadores- con las reconfiguraciones de los sujetos como portadores y productores de saberes, la centralidad de la cotidianeidad y la comunidad en el proceso formativo reafirma la condición territorializada de las pedagogías descolonizadoras. Así se deconstruye la racionalidad educativa moderna que invisibiliza la cotidianeidad, la experiencia y los saberes como parte instituyente del proceso pedagógico (Pinheiro Barbosa y Gómez, 2014), postulando el acceso a una universalidad desterritorializada (que, empero, responde a los territorios geográficos y simbólicos del norte).

\section{La apertura a lo afectivo}

Si bien el grupo de personas que integran los emprendimientos de la Interbarrial de Esteban Echeverría se reúnen con un fin productivo, en el saber-hacer técnico se forjan vínculos intersubjetivos a medida que se van conociendo, sintiéndose cómodos y compartiendo historias de vida, necesidades y problemas de la vida cotidiana. Lo subjetivo, a su vez, remite a la posibilidad de los sujetos de sentirse tales, de portar saberes, de enseñar, de ser capaces de cambiar, de dar lugar al pensar y al sentir aun en ámbitos laborales. En este sentido, nos interesa pensar lo afectivo como otra de las notas que caracterizan a las pedagogías descolonizadoras.

Esta interacción entre lo individual y lo colectivo en términos de lo afectivo formando parte de la vida productiva nos lleva a abrir el interrogante respecto a su vínculo con lo descolonizador. Por un lado, la presencia de lo afectivo en los ámbitos de trabajo autogestivos-cooperativos es presentada como un elemento disruptivo por los propios trabajadores en cuanto la concepción hegemónica del trabajo bajo patrón es significada como un espacio ajeno a los afectos (al menos como intencionalidad explícita y buscada). A contramano, en los emprendimientos analizados se revaloriza y jerarquiza el afianzamiento de las relaciones inter-subjetivas como aspecto potenciador de la formación en el trabajo y del sostenimiento de estos proyectos en el tiempo.

Analizado desde lo pedagógico, la emergencia de lo afectivo en el ámbito de trabajo puede leerse contribuyendo a una formación integral de los trabajadores que quiebra la configuración del aprendizaje como un proceso unidimensional y centralmente cognitivo —el binarismo entre razón y emoción que corre paralelo al dualismo cartesiano entre sujeto y objeto ya comentado - asumiendo a la razón junto a la emocionalidad 
de los sujetos. Esta recomposición del proceso de trabajo indudablemente reunifica lo que la modernidad colonial y el capitalismo dividieron ${ }^{4}$.

La posibilidad de reunificar lo que la modernidad disolvió y dividió en los sujetos, la mente y el cuerpo (que reenvía a la célebre frase cartesiana "pienso, luego existo") y la emoción y los afectos —en virtud de la necesaria objetividad y neutralidad - se presenta como uno de los nudos más claros en la reunificación de un sujeto potencialmente descolonizado respecto del sujeto moderno.

Este rescate de lo afectivo observado en el trabajo de campo es posibilitado por estar en colectivo, por el encuentro que se produce en un colectivo de producción en el marco de un movimiento social y político de pertenencia, en un movimiento que genera identificación. Esto conduce al próximo rasgo acerca de la naturaleza colectiva de las pedagogías descolonizadoras.

\section{El marco colectivo}

Podemos plantear a partir de las experiencias observadas y analizadas que en ellas aparece lo colectivo conformando pedagogías en dos sentidos.

En primer lugar, los vínculos que se entretejen y los saberes que se comparten en el seno del trabajo colectivo de los proyectos productivos de la Interbarrial de Esteban Echeverría dan cuenta de nuevas relaciones entre sujetos pares, entre los que circula la palabra, que deciden cómo quieren trabajar, en tanto aprenden y enseñan, que transmiten, intercambian y construyen saberes de distinto tipo (técnico, político y subjetivo). Se posicionan como sujetos con decisiones, saberes y derechos. Colectivamente, además, en estos intercambios intersubjetivos, se establecen lazos afectivos que anudan, entonces, lo productivo con lo intersubjetivo, en términos de cuidado, contención y apoyo afectivo (Guelman, Dyzel y Corvalán, 2016).

Podemos decir que en los proyectos productivos hay aprendizaje, hay reconfiguraciones subjetivas, pero solo en tanto y en cuanto hay un colectivo. Por eso el carácter pedagógico de estos proyectos que subjetivan y generan sujetos políticos es colectivo. Desde este lugar, se produce una primer tensión con la idea dominante de "intelectual y pedagogo individual"

4 La convicción de que la praxis pedagógica debe desarrollar y potenciar todas las facultades humanas ya se encuentra en la categoría marxiana de omnilaterialidad y en su propuesta de educación politécnica (Mészáros, 2008). La omnilateralidad significa dotar de sentido a la vida en todas las esferas del ser social, desarrollar todas las facultades humanas sean intelectuales o prácticas. Si bien la omnilateralidad discute la división entre lo intelectual y lo práctico en la actividad productiva, atendiendo a la preocupación por erosionar la división social del trabajo, ya remite a una idea de la formación que apunta en un sentido de integralidad. 
ya que la horizontalidad con la que circulan los saberes, y en la que se forman los sujetos, da lugar a un cierto desdibujamiento del par educador-educando y a las lógicas de saber-poder de los vínculos entre alguien que sabe y alguien que no. De allí la necesidad de pensar la categoría de intelectual colectivo en cuanto dirección colectiva de los procesos de autoorganización, entre los que se encuentran las apuestas productivas.

Los movimientos sociales en general, y como tal el de nuestro trabajo de indagación también, se consideran a sí mismos educadores; todos los espacios que llevan a cabo buscan enseñar, formar, tienen intencionalidad pedagógica. El trabajo colectivo, autogestivo y cooperativo da cuenta de algunas especificidades dentro de las actividades de los movimientos, pero se perciben y pergeñan como un ámbito de formación.

Aquí es donde ubicamos el segundo modo de una pedagogía colectiva: ya no en el modo en que se despliega, sino también desde el lugar colectivo que se imagina y piensa, aun cuando los procedimientos y los aprendizajes producidos no estén del todo claros para el colectivo que sí supone y desarrolla una manera otra de construir una alternativa pedagógica. Precisamente, esto es lo que da lugar a una tensión con la idea dominante de "intelectual y pedagogo individual", ya que el imaginario y convencimiento colectivo acerca de los ámbitos y espacios de formación, los modos de imaginarlos e implementarlos, así como la posibilidad de pensar las experiencias, deja de lado la escisión trabajo manual-trabajo intelectual propia de la modernidad colonial y capitalista, dando lugar a una praxis educativa distinta a la hegemónica. Así, podemos sostener que, en el trabajo productivo colectivo, los movimientos sociales se erigen como intelectuales y pedagogos colectivos.

\section{Algunas notas finales}

En este artículo expusimos el camino transitado y los entrecruzamientos prácticos y conceptuales realizados en torno a las pedagogías descolonizadoras desde un equipo de investigación de la Facultad de Filosofía y Letras de la Universidad de Buenos Aires en vínculo con la Interbarrial de Esteban Echeverría.

Iniciamos este artículo planteando que la inquietud por las pedagogías descolonizadoras se ha comenzado a instalar en el campo académico latinoamericano en los últimos años; no obstante, continúa siendo un tópico débilmente explorado en los estudios inscriptos en el pensamiento descolonial. Más aun, sostuvimos la centralidad de indagar la categoría pedagogías descolonizadoras en un diálogo crítico entre las prácticas y experiencias pedagógicas de los movimientos sociales y los aportes conceptuales elaborados hasta el momento. 
A continuación, abordamos una serie de notas provisorias que consideramos relevantes como rasgos de las pedagogías descolonizadoras. Esto es, la presencia en el trabajo productivo autogestivo-cooperativo de un lugar para saberes otros que ubican a los sujetos en una posición epistémica relevante; el trabajo con otros en lógicas no salariales operando como principio educativo; la apertura a lo comunitario y cotidiano o la inserción concreta de lo pedagógico-laboral de manera no aislada de los contextos vitales; las posibilidades de recomponer procesos de aprendizaje de manera que se comprometa al sujeto como un todo y no de modo escindido, haciéndole lugar a lo afectivo, y el marco colectivo que configura una pedagogía colectiva, son las características que empíricamente hemos visto intervenir en la formación de sujetos, coadyuvando a la posibilidad de que estos procesos puedan constituir sujetos en proceso potencial de descolonización. Por ello, estas notas conforman pistas para pensar las pedagogías descolonizadoras.

Nuestro acceso a las pedagogías descolonizadoras se encuentra mediado por el análisis de las pedagogías del trabajo, mencionadas al comienzo de este capítulo. En este sentido, es preciso continuar y agudizar nuestra mirada poniendo atención en los claroscuros de los procesos de formación en el trabajo, en la complejidad y las contradicciones del desarrollo concreto de esas pedagogías. Esta reflexión concerniente a las pedagogías del trabajo — dentro de las que incluimos las apuestas productivo-pedagógicas de la Interbarrial de Esteban Echeverría- nos enseñan a los estudiosos en la temática que son procesos que están siendo, que requieren una mirada abierta a las novedades que comportan así como a las contradicciones y reproducciones de lo existente.

Finalmente, cabe señalar que la conceptualización realizada en torno a las pedagogías descolonizadoras desde las praxis del trabajo requiere ser nutrida a partir del diálogo con aproximaciones pedagógicas realizadas por otros autores, donde también identificamos elementos descolonizadores: las geopedagogías (Mejía, 2011, 2015; Pinheiro Barbosa, 2015 que particularizan la relación entre prácticas pedagógicas y elementos socioculturales emergentes del territorio, la cultura y los saberes populares; las pedagogías biófilas (Cabaluz Ducasse, 2015) promotoras y comprometidas con la vida de los sujetos, las comunidades y la naturaleza, y también las pedagogías feministas en cuanto encontramos en la valorización de los afectos, la experiencia y lo testimonial un fuerte elemento descolonizador. Estas vinculaciones requieren continuar siendo indagadas y profundizadas en futuros trabajos. 


\section{Referencias}

Bonfil Batalla, G. (1997). Pensar nuestra cultura. Ensayos. Ciudad de México: Alianza.

Cabaluz Ducasse, F. (2015). Entramando pedagogías críticas latinoamericanas. Notas teóricas para potenciar el trabajo político-pedagógico comunitario. Santiago de Chile: Quimantú.

Díaz, C. (2010). Hacia una pedagogía en clave descolonial. Tábula Rasa, 13, 217-233. Recuperado de http://www.revistatabularasa.org/numero-13/08Diaz.pdf.

Dussel, E. (2012). Erótica y pedagógica. Para una ética de la liberación latinoamericana. Buenos Aires: Docencia.

Escobar, A. (2003). El lugar de la naturaleza y la naturaleza del lugar: ¿globalización o posdesarrollo? En E. Lander (comp.), La colonialidad del saber: eurocentrismo y ciencias sociales. Perspectivas latinoamericanas (pp. 113-143). Buenos Aires: Clacso.

Fernández Mouján, I. (2013). Redefinición de los alcances de la pedagogía de la liberación en sus dimensiones ética, política y cultural. Viedma: Universidad Nacional de Río Negro.

Gramsci, A. (2009). Los intelectuales y la organización de la cultura. Buenos Aires: Nueva Visión.

Guelman, A. (2015). Pedagogía y política: la formación para el trabajo en los movimientos sociales. El caso de la Escuela de Agroecología del Mocase-VC (2009-2012) (tesis doctoral). Universidad de Buenos Aires, Argentina.

Guelman, A., Dyzel, F. y Corvalán, G. (2016). Los movimientos sociales como pedagogos colectivos: el caso de la Interbarrial de Esteban Echeverría y la construcción de una pedagogía en la producción. III Encuentro Hacia una Pedagogía Emancipatoria en Nuestra América. Educación, Construcción, Disputa y Contradicción. Centro Cultural de la Cooperación, Buenos Aires, Argentina.

Guelman, A. y Palumbo, M. (2015). Prácticas pedagógicas descolonizadoras en experiencias productivas autogestionadas de movimientos sociales: el principio formativo del trabajo. Revista Interamericana de Educación de Adultos, 37(2), 47-64.

Kosik, K. (1986). Dialéctica de lo concreto. Ciudad de México: Grijalbo.

Lander, E. (1993). La colonialidad del saber: eurocentrismo y ciencias sociales. Perspectivas latinoamericanas. Buenos Aires: Clacso.

Mejía, M. (2011). Los movimientos educativos y pedagógicos del siglo xxı. Ciencia Política, 11, 128-156. Recuperado de http://www.revistas. unal.edu.co/index.php/cienciapol/article/view/41504/43118. 
Mejía, M. (2015). Educación popular en el siglo Xxı. Bogotá: Desde Abajo. Mészáros, I. (2008). La educación más allá del capital. Buenos Aires: Siglo xxI-Clacso.

Pinheiro Barbosa, L. (2015). Educación, resistencia y movimientos sociales: la praxis educativo-política de los Sin Tierra y de los Zapatistas. Ciudad de México: Librunam.

Pinheiro Barbosa, L. y Gómez, M. (2014). La educación autónoma zapatista en la formación de los sujetos de la educación: otras epistemes, otros horizontes. Intersticios de la política y la cultura. Intervenciones latinoamericanas, 3(6), 67-89. Recuperado de https://revistas.unc. edu.ar/index.php/intersticios/article/view/9065/10745.

Quijano, A. (2003). Colonialidad del poder, eurocentrismo y América Latina. En E. Lander (comp.), La colonialidad del saber: eurocentrismo y ciencias sociales. Perspectivas latinoamericanas. (pp. 201-246). Buenos Aires: Clacso.

Quijano, A. (2010). La crisis del horizonte de sentido colonial/moderno/ eurocentrado. Casa de las Américas, 50(259-260), 4-15. Recuperado de http://www.casadelasamericas.org/publicaciones/revistacasa/260/ bicentenario.pdf.

Restrepo, E. y Rojas, A. (2010). Inflexión decolonial: fuentes, conceptos y cuestionamientos. Popayán: Universidad del Cauca.

Santos, B. (2006). Renovar la teoría crítica y reinventar la emancipación social (encuentros en Buenos Aires). Buenos Aires: Clacso.

Santos, B. (2010). Refundación del Estado en América Latina. Perspectivas desde una epistemología del Sur. Lima: Instituto Internacional de Derecho y Sociedad.

Santos, B., Meneses, M. P. y Nunes, J. (2004). Introdução: para ampliar o cânone da ciência. A diversidade epistemológica do mundo. En B. de Sousa Santos (org.), Semear outras soluções: os caminhos da biodiversidade e dos conhecimentos rivais (pp. 23-105). Porto: Afrontamento.

Varela, J. y Álvarez, F. (1991). La maquinaria escolar. En Arqueología de la escuela (pp.13-54). Madrid: Ediciones de la Piqueta.

Walsh, C. (2009). Interculturalidad crítica y pedagogía de-colonial: apuestas (des) de el in-surgir, re-existir y re-vivir. En V. Candau (ed.), Educação intercultural hoje en América Latina: concepções, tensões e propostas (s. d.). Río de Janeiro: 7 Letras, puc-Río de Janeiro.

Walsh, C. (2013). Lo pedagógico y lo decolonial: Entretejiendo caminos. En C. Walsh (ed.), Pedagogías decoloniales: Prácticas insurgentes de resistir, (re)existir y (re)vivir (pp.23-68). Quito: Abya-Yala. 
